\title{
Videos virales en Chile
}

\section{Viral videos in Chile}

\author{
Javiera Rosselot \\ Departamento de Antropología, Universidad de Chile \\ jrosslazo@gmail.com
}

\section{Resumen}

Actualmente, es cada vez más habitual ver videos virales y usar sus frases en la vida cotidiana. Ya sea a través de memes, redes sociales u oralmente, los videos virales han llegado a gran parte de la población en Chile. Especialmente, es parte de la vida de los jóvenes, que son la base de informantes utilizada para este artículo. Este artículo entonces, si bien de ninguna manera intenta agotar las distintas dimensiones que alcanzan los videos virales en Chile, sirve como una primera aproximación a primero, evidenciar la vigencia de los videos virales en la cotidaneidad juvenil y segundo, ver cómo opera esta lógica que hay detrás de ver videos virales, a que se relacionan, por qué se usan.

Palabras claves: videos, viral, vida cotidiana, Chile.

\section{Abstract}

Currently, it is increasingly common to watch viral videos and use their phrases in everyday life. Whether through memes, social networks or orally, viral videos have reached much of the population in Chile. Especially, it is part of the life of young people, who are the basis of informants used for this article. However, there are practically no academic studies on the subject, at least in Chile. This article then, although in no way tries to exhaust the different dimensions that reach the viral videos in Chile, serves as a first approximation to legitimize viral videos in the juvenile daily life as a matter of social sciences. Also, helps to see how this logic operates. ¿What is behind viral videos?, ¿why are they used?

Key words: viral, videos, daily life, Chile.

\section{Introducción}

El propósito de esta investigación gira en torno a reunir información respecto al tema de los videos virales en Chile. Especialmente busca indagar en torno a la vida cotidiana y los virales. ¿Aparecen en la vida cotidiana?¿En qué situaciones?, a qué se relacionan, porque se usan. Este tema de estudio surge por su contingencia en la actualidad, a pesar de que prácticamente no existan estudios académicos respecto al tema, al menos en Chile. Para cumplir con este objetivo, que es más bien exploratorio, se hará un análisis que tomara en cuenta distintos recursos, como veremos a continuación. 


\section{Metodología}

Esta investigación se hace en base a una encuesta de google formularios. La cual fue difundida mediante Facebook entre el 31 de marzo y el 7 de abril de 2017, es decir, estuvo una semana online. La difusión fue a través de mi página personal de Facebook, siendo compartida por varios de mis contactos en esta plataforma, generando una red un poco más grande. Al cabo de una semana, fue respondida por 150 personas. De estas 150 personas, 89 se identificaron como mujeres, 57 como hombres, y otras 4 personas se identificaron con otros géneros. Estos géneros son: gender fluid, queer e intergénero. Una vez cerrada la encuesta comenzó el análisis de la información por medio del software NVivo 11 Pro. En este programa se procesan las respuestas clasificándolas a través de categorías.

La primera pregunta abierta "¿En qué situaciones usas frases de videos virales?" fue dividida en las siguientes categorías: En redes sociales, las uso poco y nada, las uso cuando se necesita humor (para bajarle el perfil a una situación tensa), las uso cuando es pertinente (la situación calza con la frase), la uso en mi vida cotidiana, la uso con amistades, la uso siempre. Es importante mencionar que estas categorías fueron construidas en base a las respuestas del formulario de Google, por lo que responden a la interpretación que los encuestados tuvieron de la pregunta, sin haber categorías dadas de antemano.

La segunda pregunta "¿Cuáles son las frases que más usas?" fue dividida en las categorías de frases de videos chilenos, frases de videos extranjeros y frases de memes. En este caso las categorías sí fueron construidas por un criterio personal, que es el de la nacionalidad de las frases. Lo anterior debido a que en los comentarios, muchas personas se refirieron a "lo chileno" como un aspecto relevante de los videos virales, algunos ejemplos son: "chile es el país del meme y del video viral irracional y gracioso" o "Creo que la vanguardia del humor Nacional está en YouTube". Además, al revisar las respuestas quedó claro que una gran mayoría respondió principalmente en base a videos chilenos, por lo que categorizar por país se tornó una buena manera de dar cuenta de ello.

La tercera "pregunta", fue en realidad una instrucción: "Describe algún video viral que te da mucha risa". Como subtítulo decía "si es que el ambiente en que lo viste influye en tu risa, no dudes en incluirlo". Las categorías fueron construidas en base a qué del video le causaba risa al encuestado, y las principales causas son el video en sí mismo, el contexto en que lo vió, la identificación con el video y la creación del video.

La cuarta pregunta fue la siguiente: “¿Hay algún video viral que te recuerde a alguien que conozcas?" Esta pregunta venía con el siguiente subtítulo: "Si es que es así, cuenta cual es el vídeo y por qué te recuerda a esa persona". Las categorías que surgieron fueron me recuerda a mi mismo, me recuerda a alguien que usa frases del video, me recuerda a alguien por la situación (por ejemplo un video de alguien que se cae borracho, me recuerda a un amigo que se cayó borracho), me recuerda a alguien por su similitud con algún personaje del video.

Antes de seguir con el análisis propiamente tal, es importante enfatizar en que estas categorías fueron construidas después de aplicar el formular, con el objetivo de que el modelo se adapte a los datos y no los datos al modelo. De manera que no se tergiversen los datos. 


\section{Análisis}

\section{Análisis de atributos}

Se llama análisis de atributos, a las preguntas, en este caso cerradas, que nos permitirán caracterizar a la muestra. En esta ocasión elegimos los atributos de edad y género, por lo que a continuación veremos cuáles son las conclusiones que podemos sacar respecto a la generalidad de las personas que respondieron este formulario.

La encuesta llegó principalmente a personas de entre 19 y 23 años, siendo especialmente intensa la representación entre los 19 y 21 años.

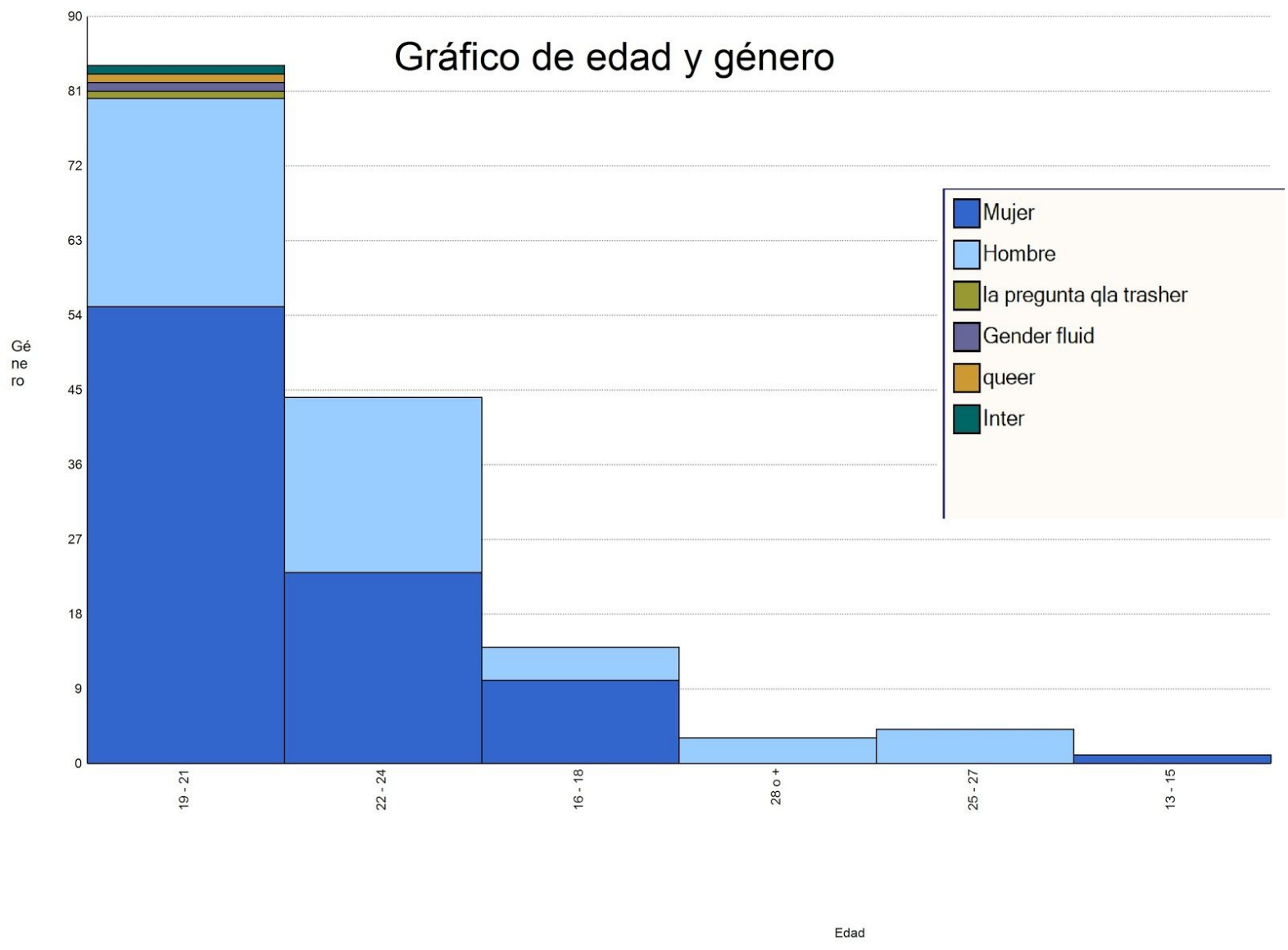

Además, como podemos ver en el gráfico, hay una sobrerrepresentación de mujeres respecto a hombres u otros géneros. Por lo que podemos decir que la muestra representa más que nada a hombres y mujeres entre los 19 y 23 años, tomando en cuenta una sobrerrepresentación de la mujer. 


\section{Análisis de nodos}

Con análisis de nodos nos referimos a la operacionalización de los datos recopilados en las preguntas abiertas. Es decir, permite hacer analizables las respuestas a través de una búsqueda de categorías que relacionen y den cuenta de las respuestas de los encuestados.

Para el análisis de nodos utilizamos 3 tipos de recursos distintos. El primero, y el más importante, fue el formulario de Google, a partir de este recurso fue que se generaron las categorías (nodos). El segundo fue el análisis de una página de Facebook llamada "Memes chilenos chistosos". Mientras que el tercero, y con menos incidencia en el análisis, fue un vídeo de youtube titulado: ¿Cómo hacer un video viral? de la BBC. Este análisis se realizará tomando como guía las preguntas y categorías expuestas en la metodología, ya que a partir de estas se analizaron los otros recursos. Primero, revisaremos cada pregunta por separado para posteriormente ver las relaciones entre nodos de distintas preguntas.

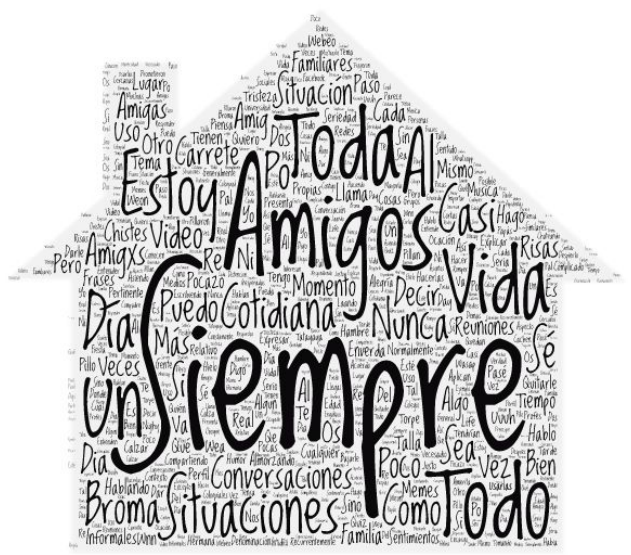

Para la primera pregunta, ¿En qué situaciones usas frases de videos virales?, organizaremos las categorías presentadas en la metodología por frecuencia de respuestas. Las categorías, de mayor a menor frecuencia, son las siguientes. La respuesta que más se repitió fue "siempre", las que le siguen son "con amistades", "en la vida cotidiana", "cuando es pertinente" y "cuando se necesita humor". Entre las respuestas menos frecuentes se encuentra "las uso en redes sociales" y "las uso poco y nada". De esto podemos concluir, que la mayoría de los encuestados usan frecuentemente frases de videos virales, y que dentro de las personas que respondieron la encuesta, son minoritarios los que no suelen usar estas frases.

La segunda pregunta refiere a las frases más usadas, y fue categorizado por nacionalidad. Los resultados fueron que un $77 \%$ de las frases más usadas son chilenas, mientras que un $11 \%$ son extranjeras y el otro $12 \%$ son de memes, que no califican como frases de videos virales. De estos resultados podemos concluir que el hecho de que el video sea chileno parece influir en el interés de la muestra, y por otro lado, que hay una confusión respecto a la diferencia entre videos virales y memes.

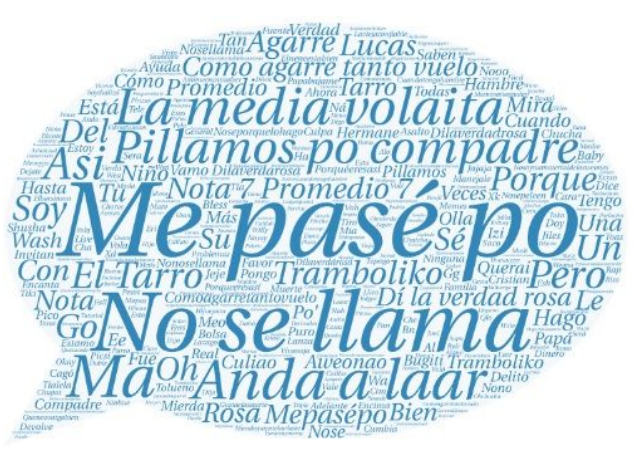




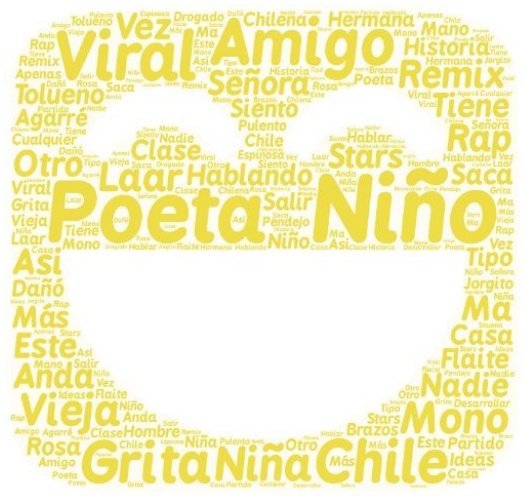

El tercer tema que abordamos fue la descripción de algún video que al encuestado le pareciera gracioso. Las categorías fueron construidas en base a qué del video le causaba risa al encuestado, y las principales causas son "el video en sí mismo", "el contexto en que lo vió", la "identificación con el video" y el "hecho de que el video haya sido creado". De estas categorías la que más se repitió fue por amplia mayoría "el video en si mismo". Como secundarias, tanto identificación como contexto parecen estar en el mismo nivel, mientras que el "hecho de que el video haya sido creado" es la respuesta menos frecuente.

La cuarta pregunta hace referencia a los recuerdos respecto a videos virales. En este tema surgieron recuerdos debido a que alguien "usa la frase", "se parece, "vivió una situación parecida" o bien "le recuerda a sí mismo". De estas categorías, la más repetida fue que le recuerda a alguien que vivió una situación parecida, de cerca la siguen el "se parece" y "usa la frase". El me recuerda a mi mismo, sin embargo, fue una respuesta minoritaria.

\section{Comparación de nodos}

Ahora bien, una vez presentados los resultados, podemos proceder a cruzar los distintos temas a través del software Nvivo 11 Pro, para ver si ciertas categorías están o no relacionadas.

Casi la mitad de las personas que recuerdan personas por una situación compartida relacionada al viral, dicen usar siempre frases de videos virales. Para seguir relacionando recuerdos -lo que correspondería a la cuarta pregunta- y situaciones -que corresponde a la primera pregunta- podemos decir que: a pesar de que 20 personas usan frases de videos virales en su vida cotidiana, solo en 4 casos lo relacionan también a situaciones compartidas por las que recuerdan a alguien.

Además, hay evidencia de que la gran mayoría de las personas que encuentran los videos chistosos en sí mismos, ven principalmente videos chilenos. Relacionado a lo anterior, de las 20 personas que recuerdan a una persona porque usa frecuentemente una frase de algún video, 17 usan frases chilenas. Entonces podemos decir que hay evidencia que respalda que en Chile la gente que suele recurrir a frases de videos virales, tiende a usar frases de videos chilenos. Entonces, los recuerdos, ya sean por uso de la frase, o por el video en sí mismo, tienden a ser respecto a videos creados en este país.

Por último, antes de concluir, haremos un pequeño análisis por género. A este respecto, podemos decir que de las 49 personas que respondieron que siempre usan frases de videos virales se ven representados un $39 \%$ de las mujeres y un $23 \%$ de los hombres que respondieron esta encuesta. 


\section{Conclusiones}

A modo de conclusión, podemos ver que los videos virales pasan a ser parte de los códigos cotidianos de las personas, dejando de ser videos solamente. Se desdoblan en recuerdos, asociaciones, recursos discursivos, e incluso en elementos "identitarios" como se puede ver en esta respuesta: "El video de 'como agarre tanto vuelo', me recuerda a mis amigas del colegio; un tiempo (hace como 5 años) lo imitábamos tanto que a nuestro grupo de whatsapp le pusimos nombre por el video. Y hasta terminamos yendo al cumpleaños del niño que choca con el árbol en el video".

Sin embargo, una de las limitaciones que puede haber tenido este estudio es que, de la manera en que fue difundido, se puede haber entendido que la encuesta estaba hecha solo para personas interesadas en videos virales, y que suelen usarlo en su vida cotidiana como fue demostrado a través de los resultados de la primera pregunta. En ese sentido, se produce un sesgo, ya que hay perspectivas que quedan fuera por el simple hecho de no haberse considerado un usuario pertinente para responderla. 
ANEXO 1: Categorías de análisis

\begin{tabular}{|c|c|c|c|}
\hline 1. Nombre & $\operatorname{\omega og}$ & Recursos & Referencias \\
\hline Frases & & 0 & 0 \\
\hline Videos & & 0 & 0 \\
\hline Extranjero & & 1 & 19 \\
\hline Chilenos & & 2 & 130 \\
\hline Memes & & 1 & 19 \\
\hline 1. Nombre & $\operatorname{cog}$ & Recursos & Referencias \\
\hline Recuerdos & & 0 & 0 \\
\hline A uno mismo & & 1 & 7 \\
\hline Por & & 1 & 1 \\
\hline Situación & & 2 & 31 \\
\hline Similitud & & 3 & 27 \\
\hline Usa la frase & & 1 & 20 \\
\hline A Nombre & 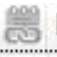 & Recursos & Referencias \\
\hline Causas de risa & & 0 & 0 \\
\hline La creación del video & & 1 & 1 \\
\hline El video en sí mismo & & 2 & 56 \\
\hline El vídeo en el contexto & & 2 & 7 \\
\hline Identificación & & 4 & 7 \\
\hline Situaciones & & 1 & 152 \\
\hline Pocoy nada & & 1 & 7 \\
\hline Pertinente & & 1 & 15 \\
\hline Cotidiano & & 1 & 20 \\
\hline Amigos & & 1 & 29 \\
\hline Siempre & & 1 & 49 \\
\hline Frases videos & & 1 & 7 \\
\hline Redes sociales & & 2 & 5 \\
\hline Humor & & 2 & 10 \\
\hline
\end{tabular}




\section{ANEXO 2: Encuesta}

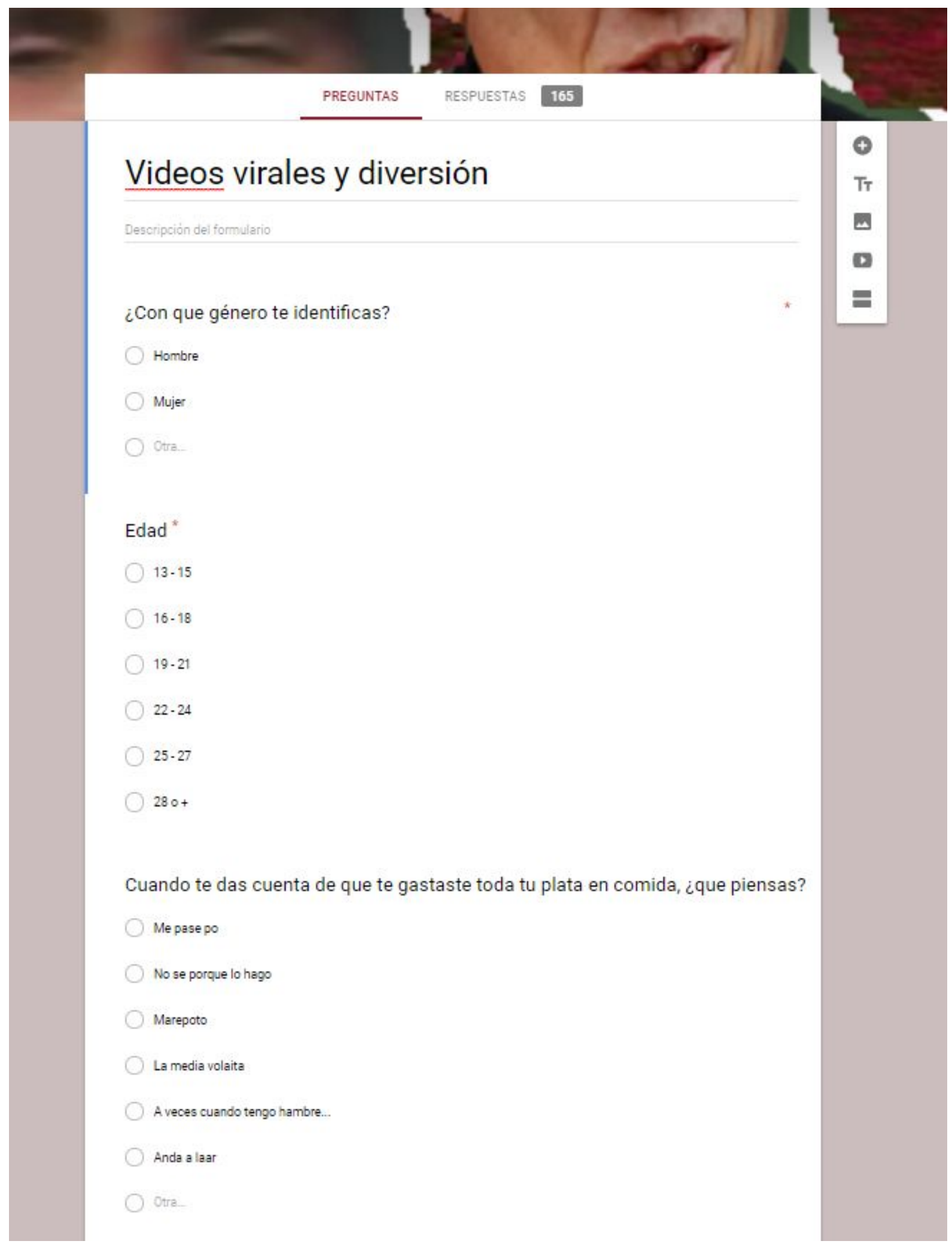


Si te pillan robándote un choclo, ¿que dirías?

Como agarre tanto vuelo

Hay que saber subir y bajar

Apaga la camara conchetumaire, nos pillaron

Anda a laar

Me llevaron engañado pa chillan

Vamo a irno, pero vamo a imo como yo quiero

Otra.

¿En qué situaciones usas frases de videos virales?

Texto de respuesta largo

¿Cuáles son las frases que más usas?

Texto de respuesta largo

Describe algún video viral que te da mucha risa

Si es que el ambiente en que lo viste influye en tu risa, no dudes en incluirlo.

Texto de respuesta largo

¿Hay algún video viral que te recuerde a alguien que conozcas?

Si es que es asi, cuenta cual es el video y por qué te recuerda a esa persona

Texto de respuesta largo

¿Quieres agregar otro comentario o experiencia?

Texto de respuesta largo 
